\title{
A teoria de Jean Piaget como princípio para o desenvolvimento das inovações
}

\author{
The theory of Jean Piaget as a principle for the development of innovations \\ La teoría de Jean Piaget como principio para el desarrollo de innovaciones
}

\author{
KAREN SELBACH BORGES* \\ LÉA DA CRUZ FAGUNDES**
}

\begin{abstract}
$\diamond$
RESUMO

Neste trabalho, buscou-se mostrar que a teoria de Jean Piaget explica os mecanismos cognitivos utilizados pelos inventores nas suas criações. Sabendo-se que o processo de criação é diferente para cada pessoa, procurou-se, através de uma metáfora, o "ciclone da criação", representar as etapas desse processo. Por fim, desejou-se promover uma reflexão sobre a seguinte questão: sabendo-se que os mecanismos descritos por Piaget são efetivos para a produção de invenções e que estas são importantes para as inovações que impulsionam o avanço da humanidade, como promover, de forma adequada, o desenvolvimento desses mecanismos para que os jovens de hoje sejam os inovadores de amanhã?
\end{abstract}

Palavras-chave: Inovação. Invenção. Mecanismos cognitivos. Jean Piaget.

\begin{abstract}
This paper aim to show that the theory of Jean Piaget explains the cognitive mechanisms used by inventors in their creations. Knowing that the creative process is different for each person, we seek through a metaphor, the "cyclone of creation", represent the steps of this process. Finally, we wish to promote a reflection on the following question: given that the mechanisms described by Piaget are effective for the production of inventions and that these are important for the innovations how to promote the development of mechanisms that will turn the youth of today in tomorrow's innovators.
\end{abstract}

Keywords: Innovation. Invention. Cognitive mechanisms. Jean Piaget.

\section{RESUMEN}

En este trabajo se muestra que la teoría de Jean Piaget explica los mecanismos cognitivos utilizados por los inventores en sus creaciones. Sabiendo que el proceso de creación es diferente para cada persona, se busca a través de una metáfora, el "ciclón de la creación", en representación de las etapas de este proceso. Por último, queremos promover una reflexión sobre la siguiente cuestión: dado que los mecanismos descritos por Piaget son eficaces para la producción de invenciones y que éstos son importantes para las innovaciones que impulsan el progreso de la humanidad, como promover el desarrollo de estos mecanismos para que los jóvenes de hoy son los innovadores del mañana?

Palabras clave: Innovación. Invención. Mecanismos cognitivos. Jean Piaget.

\footnotetext{
* Possui Bacharelado em Informática pela Pontifícia Universidade Católica do Rio Grande do Sul (1997) e mestrado em Ciência da Computação pela Pontifícia Universidade Católica do Rio Grande do Sul (2000). Atualmente é aluna de doutorado em Informática na Educação pela Universidade Federal do Rio Grande do Sul. Atua como professora EBTT do Instituto Federal de Educação, Ciência e Tecnologia do Rio Grande do Sul, câmpus Porto Alegre. Desenvolve pesquisa sobre tecnologias educacionais, inovação em educação e aprendizagem colaborativa. E-mail: <karen.borges@poa.ifrs.edu.br>.

** Possui graduação em Pedagogia pela Universidade Federal do Rio Grande do Sul (1972), graduação em Psicologia pela Universidade Federal do Rio Grande do Sul (1988), mestrado em Educação pela Universidade Federal do Rio Grande do Sul (1977) e doutorado em Ciências-Psicologia pelo Instituto de Psicologia da Universidade de São Paulo (1986). Atualmente é professora titular aposentada da Universidade Federal do Rio Grande do Sul, docente permanente, convidada no Mestrado em Psicologia Social e Institucional/UFRGS, docente no Programa de Pós-Graduação Informática na Educação/ UFRGS, coordenadora de pesquisa no Laboratório de Estudos Cognitivos(LEC/UFRGS) e assessora do Ministério de Educação. Tem experiência na área de Psicologia do Desenvolvimento Cognitivo, com ênfase em Aprendizagem, atuando principalmente nas seguintes áreas: informática educativa, educação a distância e psicologia cognitiva.E-mail: <leafagundes@gmail.com>.
} 


\section{INTRODUÇÃO}

Os problemas do mundo estão cada vez mais complexos e para solucioná-los é preciso ideias criativas e soluções não convencionais. É preciso inovação!

Justo (2001) chama a atenção para o "mundo mutante" em que se vive. Um mundo onde as transformações ocorrem de forma tão rápida que, por vezes, nem se dá conta de que elas aconteceram e que nelas já se está envolvido. As mudanças, como bem se sabe, são potenciais geradoras de problemas que, olhando sob uma perspectiva otimista, podem se apresentar como elementos de motivação para o desenvolvimento de soluções criativas e inovadoras.

Assim, o termo inovação pode ser entendido como a criação de uma solução não convencional, permeada de valores, para um problema que o mundo apresenta. É importante destacar que o termo "valores" não é apenas uma referência aos ganhos financeiros advindos da inovação em si. Por exemplo, o uso da robótica nos processos de ensino e aprendizagem é uma das inovações em educação que tem se destacado nos últimos tempos. $\mathrm{O}$ valor não está no robô que será criado pelos estudantes, mas sim no aumento do interesse dos alunos pelos temas envolvidos nos projetos de robótica, no desenvolvimento da criatividade, da colaboração, da capacidade de resolução de problemas, entre outros.

O processo de geração de uma inovação é, na visão de Brown (2010), iterativo e não linear, com um ponto de partida e dois pontos de referência. Começa pela inspiração, quando é identificado o problema que irá motivar o desenvolvimento da solução. A idealização é o momento de geração de ideias, da experimentação, da invenção e dos testes. E a implementação ocorre quando a solução criada é posta em ação. O produto desse processo deve dar "ênfase nas necessidades humanas fundamentais, em oposição a desejos efêmeros ou artificialmente manipulados" (BROWN, 2010, p. 19).

A estrutura desse processo sofre variações conforme o autor que se propõe a explicar o desenvolvimento das inovações, mas a etapa de idealização (ou ideação) está presente em todas elas, demandando, principalmente, habilidades criativas. Santos define a criatividade como

o processo que gera a ideia, o período em que o autor busca um planejamento estratégico para a efetivação do projeto, enquanto que a inovação caracteriza-se pela prática, concretização e implementação das ideias que o método criativo desenvolveu (SANTOS et al., 2001, p. 16).

Ou seja, a criatividade está relacionada com o processo mental de geração de novas ideias e a inovação é a execução dessas ideias criativas.
Por volta de 1800, Ada Byron, hoje reconhecida como a primeira programadora de computadores da história, utilizava o termo imaginação como sinônimo de criatividade. Em um ensaio de 1841, ela descreve a imaginação como a "faculdade de fazer combinações. Ela reúne coisas, fatos, ideias em combinações novas, originais, infinitas e sempre em mutação [...] é ela que penetra os mundos invisíveis da ciência à nossa volta" (ISAACSON, 2014, p. 24). Aproximadamente 80 anos depois, Jean Piaget iniciou sua pesquisa sobre os processos cognitivos e sobre o desenvolvimento do pensamento humano. Assim como Ada, ele também acreditava que a criatividade se dava a partir das "combinações novas, originais e sempre em mutação". Para Piaget, os elementos que causam a perturbação do equilíbrio (como os problemas e as dúvidas) são os responsáveis pelo acionamento de mecanismos que levam às mudanças na estrutura conceitual do sujeito, tais como assimilações (que correspondem à incorporação de novos conceitos ao sistema conceitual pré-existente) e acomodações (que estão relacionadas com as modificações no sistema conceitual). Esses mecanismos são parte do processo de abstração reflexiva que constitui a essência dos "atos de criatividade intelectual” (PIAGET, 2001, p. 15) e é fundamental para o desenvolvimento do pensamento lógico.

Além da criatividade e do raciocínio lógico, aqueles que se propõem a trabalhar com inovação costumam apresentar características pessoais marcantes, tais como curiosidade, iniciativa, pró-atividade, persistência, abertura ao novo, autorregulação, capacidade de trabalhar de forma colaborativa e multidisciplinar. Christesen, Dyer e Gregersen (2012) ressaltam que as pessoas inovadoras possuem cinco competências bem desenvolvidas: associar, questionar, observar, contatar pessoas e experimentar.

Os inovadores "pensam diferente" [...] suas mentes são excelentes para combinar ideias que não estão relacionadas de maneira óbvia, para produzir ideias originais (chamaremos essa competência cognitiva de "pensamento associativo" ou "associação"). Mas, para pensar de forma diferente, os inovadores têm que agir de forma diferente. Todos eram indagadores e faziam perguntas que desafiavam o status quo. Alguns observavam o mundo com uma intensidade que ia além do normal. Outros se ligavam pela internet às mais diversificadas pessoas na face da Terra. Outros ainda colocavam a experimentação no centro de sua atividade de inovação. Quando levadas adiante de forma consistente, essas ações davam início a um pensamento associativo para produzir novos negócios, produtos, serviços e/ou processos (CHRISTESEN, DYER e GREGERSEN, 2012, p. 7).

As cinco competências apontadas estão, de certa forma, alinhadas com a teoria da construção do 
conhecimento de Piaget, uma vez que este defende o aprendizado através do questionamento, da exploração, da experiência, da tentativa e erro, e da cooperação Assim, tomando como base a teoria de Piaget, propõe-se analisar a relação desta com a temática da inovação.

O texto que segue está estruturado em três seções. Na seção 1 serão apresentadas as bases da teoria de Jean Piaget, fazendo referência a sua aplicação no processo de invenção. A seção 2 demonstra como o processo de invenção pode ser representado na forma de um ciclone, assim como a espiral proposta por Piaget para o processo de abstração reflexionante. Conclui-se este artigo com algumas questões que visam a promover uma reflexão sobre o seguinte ponto: sabendo-se que os mecanismos descritos por Piaget são efetivos para a produção de invenções e que estas são importantes para as inovações que impulsionam o avanço da humanidade, como promover, de forma adequada, o desenvolvimento desses mecanismos para que os jovens de hoje sejam os inovadores de amanhã?

\section{A RElaÇão da teoria de Piaget COM A INOVAÇÃO}

A partir da análise das obras de Piaget, é possível concluir que o mesmo não trata da inovação, que é um termo advindo da área de administração e negócios e que foi introduzido pelo economista austríaco Joseph Schumpeter (1997), autor da Teoria do Desenvolvimento Econômico. Piaget fala em inventividade e criatividade; esta última sendo a capacidade de criação de algo novo, do ponto de vista científico. Ao afirmar que "o que se pretende, para o futuro, é moldar indivíduos capazes de produzir ou de criar, e não apenas de repetir", Piaget (2011, p. 27) deixou registrada sua preocupação com o desenvolvimento cognitivo de crianças e adolescentes, de modo que estes, cada um a seu tempo, sejam sujeitos criativos e inovadores.

Para De Masi (2005, p. 19), a criatividade é o mecanismo "com o qual o homem tenta derrotar, tenaz e incessantemente, os seus inimigos de todos os tempos: o cansaço e a solidão, a ignorância e a feiúra, a tradição e o autoritarismo, a miséria, a dor e a morte". Logo, as inovações desenvolvidas ao longo dos tempos tiveram como propósito melhorar a qualidade de vida humana e satisfazer as suas necessidades. Segundo Piaget,

toda ação, isto é, todo movimento, pensamento ou sentimento, corresponde a uma necessidade. Toda criança ou adulto só executa alguma ação exterior ou mesmo inteiramente interior quando impulsionada por um motivo e este se traduz sempre sob a forma de uma necessidade (uma necessidade elementar ou um interesse, uma pergunta, etc) (PIAGET, 1999, p. 16).
Assim, uma ideia criativa e inovadora se dá pela busca de solução para um problema. Este pode ser entendido, na perspectiva de Piaget, como um elemento de desequilíbrio, como uma perturbação na estrutura cognitiva do sujeito que, por sua vez, irá realizar uma série de processos mentais que o levarão a um novo estado de equilíbrio. Pocessos que, na maioria das vezes, são inconscientes e envolvem assimilações e acomodações, e não estão associados apenas à mudança de faixa etária, mas sim à função das construções cognitivas que se sucedem na criança.

Segundo o autor, existem quatro fatores que influenciam o desenvolvimento de um conjunto de estruturas cognitivas mais elaboradas:

\begin{abstract}
O primeiro de todos, a maturação (...) uma vez que esse desenvolvimento é uma continuação da embriogênese; o segundo, o papel da experiência, dos efeitos do ambiente físico na estrutura da inteligência, o terceiro, a transmissão social em sentido amplo (transmissão por linguagem, educação, etc); e o quarto fator, que é com freqüência negligenciado, mas que me parece fundamental e até o fator principal. Chamarei a este fator de equilibração, ou se preferirem, de autoregulação (PIAGET, 1995, p. 2).
\end{abstract}

\subsection{A maturação}

A maturação tem um sentido de amadurecimento das estruturas físicas, as quais tornam "possível uma organização sensório-motora que irá promover a constituição do pensamento e de seus instrumentos simbólicos, que implicam a construção de uma nova lógica, que se defronta com novos problemas e o ciclo se repete" (PIAGET, 1975, p. 97). Piaget definiu quatro estágios de desenvolvimento: (i) sensório-motor: ocorre até os 2 anos de idade; (ii) pré-operatório: ocorre na faixa dos 2 aos 7 anos de idade; (iii) operatório concreto: ocorre na faixa dos 7 aos 11 anos de idade; (iv) operatório formal: ocorre na faixa dos 12 aos 15 anos de idade. São nos dois últimos estágios que, segundo Piaget, formam-se as bases para o pensamento científico.

No nível operatório concreto, a criança desenvolve os mecanismos cognitivos necessários para a realização de operações de classificação, serialização e sequenciação necessárias para separar objetos em categorias de acordo com características percebidas por meio de semelhanças ou diferenças; colocar em ordem um conjunto de objetos, considerando a ordem linear de grandeza desses elementos; e fazer suceder, a cada elemento, um outro. Já no nível operatório formal,

o adolescente começa a raciocinar lógica e sistematicamente. Esse estágio é definido pela habilidade de engajar-se no raciocínio proposicional. 
As deduções lógicas podem ser feitas sem o apoio de objetos concretos. O pensamento hipotético-dedutivo é o mais importante aspecto apresentado nessa fase de desenvolvimento, pois o ser humano passa a criar hipóteses para tentar explicar e sanar problemas (PIAGET, 1971, p. 77).

É a partir do momento em que a pessoa atinge o estágio formal que as inovações se tornam possíveis. Nesse nível, o sujeito é capaz de representar o seu modelo mental de forma abstrata, através de diagramas e equações, e de realizar uma série de operações lógicas que possibilitam garantir a identidade, a negação, a reciprocidade e a correlação entre proposições. Essas operações permitem verificar uma invenção sob diferentes condições. Se aquilo que foi criado for testado diversas vezes em condições idênticas, com as mesmas variáveis, e apresentar sempre o mesmo resultado, está garantida a identidade. Da mesma forma, se aquilo que foi criado for testado em condições opostas, com as mesmas variáveis, e apresentar resultados também opostos, está garantida a reciprocidade. Já a negação permite identificar os erros, enquanto a correlação possibilita observar os resultados alternativos de um teste.

Isso explica por que as invenções são produzidas, em geral, depois de o jovem atingir a maturidade física e mental necessárias para suportar plenamente o processo de equilibração responsável pela criação do novo.

\subsection{A experiência}

O processo de criação se dá a partir da ação do sujeito sobre o objeto. Isto envolve "deslocá-los, ligá-los, combiná-los, dissociá-los e reuni-los novamente" (PIAGET, 1975, p. 72). De fato, uma invenção surge a partir de vários experimentos. Começa com um ou mais protótipos, que sofrem ações que, por sua vez, levam a ajustes e transformações, até se chegar ao produto final. Esses experimentos fazem com que o inventor, ao longo do processo de criação, vá aprendendo sobre aquilo que é o seu objeto de estudo. Isso leva a alterações no objeto, que por sua vez geram novas informações, que levam o inventor a fazer mais alterações e assim sucessivamente, em um ciclo onde o sujeito altera o objeto e o objeto altera o sujeito.

Graças à tomada de consciência, esse processo é possível, a partir da constatação de um êxito ou fracasso, o que torna possível identificar os mecanismos responsáveis pelo resultado. Em caso de fracasso, trata-se de estabelecer por que ele ocorreu e "a partir do dado de observação relativo à ação (sua finalidade ou direção global), ele vai concentrar a atenção nos meios empregados e em suas correções ou eventuais substituições" (PIAGET, 1977, p. 199).

Entretanto, a tomada de consciência não está limitada à ação sobre o objeto (fazer), mas também envolve a interiorização da ação (compreender), a qual permite reconhecer os mecanismos cognitivos empregados (abstrações, reflexionamentos e operações lógico-matemáticas) e transformar um esquema de ação em conceito, por exemplo na forma de "representações semiotizadas (linguagem, imagens mentais, etc)" (PIAGET, 1977, p. 210). Essas conceituações são úteis para

explicar o que descobrimos para outras pessoas e para nós mesmos. Ela nos auxilia a clarear nossas ideias e a aperfeiçoar cadeias desordenadas de ações e/ou pensamentos em coordenações mais simples e essenciais (MANTOAN, 1994, p. 14).

Isso ajuda a esclarecer a importância da documentação técnica de uma invenção (relatório descritivo e desenhos, entre outros), para o processo de obtenção de patentes ou registros de propriedade intelectual (INPI, 2015).

\subsection{A transmissão social}

A transmissão social está relacionada com as questões culturais e educacionais e com a influência destas sobre o sujeito. Sabe-se que o contexto em que um sujeito está inserido é determinante na sua formação e, consequentemente, no resultado das suas criações. Tomese como exemplo Santos Dumont, que cresceu em meio a motores a vapor, teve acesso às obras de Júlio Verne e viveu na França, na exata época em que surgiam os primeiros dirigíveis e automóveis (DUMONT, 1986).

Em um processo de criação, a participação de outros pode ajudar a trazer novos elementos de pesquisa, novas questões, novas informações e novas perspectivas sobre o problema, que, por sua vez, poderão ajudar no aprimoramento da invenção. Por isso a importância dos intercâmbios entre pesquisadores que, nestas oportunidades, podem trocar informações, fazer cursos de especialização e participar de estágios com outros pesquisadores.

Segundo Piaget, em uma relação de trocas intelectuais entre dois indivíduos, "para que o equilíbrio ocorra, são necessários interlocutores que possam cumprir certas regras e um determinado tipo de relação social em que elas sejam possíveis." (LA TAILLE, 1992, p. 14). As regras que Piaget coloca são: "Um sistema comum de signos e definições; uma conservação das proposições válidas obrigando aquele que as reconhece como tal; uma reciprocidade de pensamentos entre os interlocutores" (LA TAILLE, 1992, p. 14).

Piaget apresenta a coação e a cooperação como possíveis relações sociais, num contexto de trocas intelectuais. A coação não contribui com o processo de construção do conhecimento, pois não há trocas. Nessa relação existe aquele que impõe a verdade e aquele que a recebe e não a questiona. Já a cooperação, segundo 
La Taille (1992, p. 20), "é o tipo de relação interindividual que representa o mais alto nível de socialização. E é também o tipo de relação interindividual que promove o desenvolvimento", pois exige dos envolvidos análise de diferentes pontos de vista, argumentação e apresentação de provas.

Somente através do trabalho cooperativo é que se tornou possível o desenvolvimento de inovações modernas como a estação espacial internacional, os tocadores de música ("MP3 players"), os aplicativos de carona ou a "water ATM" (considerada uma inovação social). Independentemente do nível de complexidade da inovação, o envolvimento de pessoas de diferentes áreas, com diferentes experiências e conhecimentos, possibilita a criação de processos ou produtos mais eficientes, baratos e fáceis de usar; consequentemente, com maior abrangência e impacto na vida das pessoas.

\subsection{A equilibração}

A equilibração é considerada por Piaget como o elemento que coordena de forma consistente os outros três fatores: maturação, experiência e transmissão. Além disso, o processo de equilibração é para Piaget a fonte real do progresso, pois os desequilíbrios "obrigam um sujeito a ultrapassar o seu estado atual e procurar seja o que for em direções novas [...] Os desequilíbrios constituem o motor da investigação, porque sem eles, o conhecimento manter-se-ia estático" (PIAGET, 1977, p. 23 e 24).

Assim como nos demais tipos de sistemas (mecânico, hídrico, biológico, etc), o sistema conceitual também busca uma forma de equilíbrio. Entretanto, o processo de equilibração visa à elaboração de um sistema conceitual melhor (mais amplo ou profundo), ao contrário de um sistema mecânico, por exemplo, que procura a estabilidade.

O processo de equilibração ocorre graças a um processo contínuo de assimilação e acomodação. "Na relação entre sujeito e objeto de conhecimento, a assimilação representa a ação do sujeito sobre o objeto, enquanto que a acomodação exprime a ação do objeto sobre o sujeito" (MONTENEGRO e MAURICENAVILLE, 1998, p. 118).

Dessa forma, a assimilação é a responsável por incorporar elementos exteriores (dados dos objetos, por exemplo) aos esquemas sensório-motores ou conceituais do sujeito. Já a acomodação é a responsável por criar ou alterar os esquemas de assimilação existentes. A assimilação permite, por exemplo, a identificação de propriedades de objetos a fim de organizá-los em classes. O processo de acomodação é o responsável pela incorporação dessas classes ao sistema conceitual do sujeito.

\footnotetext{
1 http://www.sarvajal.com.
}

Logo, a assimilação e a acomodação são processos indissociáveis e complementares e explicam como se dá o incremento do sistema conceitual. Mas, conforme Montenegro e Maurice-Naville (1998), desempenham um papel restrito no desenvolvimento cognitivo, não sendo suficiente para explicar os processos de abstração envolvidos na construção de um novo conhecimento.

\subsection{Abstração reflexionante}

Todo novo conhecimento é, na visão de Piaget, produto de um processo de abstração reflexionante que, segundo Montenegro e Maurice-Naville, ocorre em três tempos:

primeiramente a abstração propriamente dita, que consiste em depreender certos modos de organização dos conhecimentos do sujeito; depois, o reflexionamento, que torna a projetar o que foi abstraído em um plano de conhecimento superior; enfim, a reflexão ou reconstrução em um novo plano (MONTENEGRO e MAURICE-NAVILLE, 1998, p. 92).

Sobre a reflexão, Piaget afirma que, quando alguém reflete sobre algo,
a pessoa não está somente refletindo em um nível superior, mas reconstruindo em um nível mais avançado o que já existia em um inferior. O nível superior é sempre majorante, mais abrangente. Quando alguém reflete em um plano mais avançado, precisa enriquecê-lo com novos elementos. Então tem de estendê-lo, bem como transpô-lo a um segundo nível (PIAGET, 2001, p. 16).

Para ilustrar esse processo, recorre-se ao exemplo da Máquina de Turing, que é um dos mais importantes conceitos da era digital. Kurt Gödel, lógico austríaco, elaborou o "teorema da incompletude", que demonstrava que existem afirmações que não podem ser comprovadas nem como verdadeiras nem como falsas. Quando apresentado a esse teorema, Turing foi instigado a pesquisar se existiria algum processo mecânico que pudesse ser usado para determinar se uma afirmação específica é comprovável. Turing gostou do conceito de "processo mecânico" e, a partir disso, elaborou uma máquina imaginária para resolver o problema. Essa máquina (Máquina de Turing) é um modelo abstrato de computador. Uma das suas primeiras aplicações foi na construção de máquinas físicas para quebrar os códigos secretos das comunicações alemãs durante a Segunda Guerra Mundial (ISAACSON, 2014).

Nesse caso, pode-se reconhecer como abstração o conceito de "processo mecânico". O reflexionamento está na elaboração da Máquina de Turing, criada a partir desse 
conceito. A reflexão foi realizada ao aplicar a Máquina de Turing na construção das máquinas de decodificação.

\section{O PROCESSO DE CRIAÇÃO EM QUATRO ETAPAS}

Alessandrini (2004, p. 54) afirma que "a ação criadora é profundamente humana, pois é diante de desafios que lhe são significativos que cada pessoa cria". Dessa forma, o processo de criação é diferente para cada pessoa, pois será influenciado pelos conhecimentos e pelas experiências anteriores, pelas habilidades e competências, pelas motivações e objetivos, pela capacidade do sujeito de lidar com os erros e frustrações, de antecipar e planejar. Assim, a descrição de um processo de criação, genérico o suficiente para abranger todas as possibilidades individuais, só pode ser feita com base em abstrações ou metáforas.

Escolhe-se essa última para representar o processo de criação na forma de um ciclone. Tudo começa quando este "toca o chão", ou seja, quando o elemento que irá desencadear a criação deixa de ser apenas curiosidade e é formalizado como uma pergunta. Assim, quatro momentos se sucedem dentro desse "ciclone da criação":

1. Perguntar: nessa etapa são identificados os problemas e formuladas as perguntas que irão orientar a criação da invenção. No século XIX, Charles Babbage questionou: "É possível calcular de forma mecânica logaritmos, senos, cosseno e tangentes?" (ISAACSON, 2014, p. 29). Essa pergunta desencadeou uma série de pesquisas e criações que culminaram na invenção do computador, considerada a maior inovação do século XX.

2. Conhecer: momento em que o sujeito obtém informações mais aprofundadas sobre os elementos que compõem o problema. No caso da Máquina Diferencial (a primeira criada), foi necessário que Babbage conhecesse profundamente como eram feitos os cálculos, os quais desejava poder automatizar.

3. Compreender: momento que está intimamente ligado ao conhecer, pois quanto mais se conhece o objeto de pesquisa, melhor se compreende o problema e a solução a qual se deseja chegar. Conhecendo como eram feitos os cálculos, Babbage compreendeu que a

principal complexidade era definir como "levar" e "emprestar" números quando necessário [...] Com base nos equipamentos de Pascal, Babbage teve algumas idéias engenhosas que permitiriam que as rodas dentadas e os eixos fizessem o cálculo (ISAACSON, 2014, p. 31).
4. Criar: é o momento em que a novidade é criada e testada. Nesse ponto, em que a invenção é posta em uso, eventuais problemas ou questionamentos (a respeito do desempenho, eficácia, aceitação pelo público alvo, entre outros) podem surgir. Esse é o início de novo ciclo de perguntar, conhecer, compreender e criar.

Ao se questionar sobre a possibilidade de criar uma máquina de propósito geral, ou seja, que resolvesse qualquer tipo de tarefa, Babbage criou a Máquina Analítica, que podia ser programada quantas vezes fossem necessárias através do uso de cartões perfurados. Essa ideia de usar cartões, Babbage "tomou emprestado" dos teares automáticos inventados por Joseph-Marie-Jacquard. Sobre isso, Ada Byron escreveu

Os limites da aritmética foram ultrapassados no momento em que surgiu a ideia de aplicar cartões. A Máquina Analítica não é o mesmo que as simples máquinas de calcular. Ela tem uma posição totalmente própria. Ao permitir que um mecanismo combine símbolos em geral, estabelece-se uma ligação única entre as operações concretas e os processos mentais abstratos (ISAACSON, 2014, p. 44).

Observa-se que, ao adaptar a invenção de outro à sua, para poder resolver o problema de criação de uma máquina que pudesse ser reprogramada infinitas vezes, Babbage não só expandiu o conceito de máquina de calcular como também aumentou a sua complexidade. A partir da Máquina Analítica, tornou-se necessário também saber programar, competência desenvolvida por Ada Byron.

A Figura 1 apresenta de forma esquemática o "ciclone da criação":

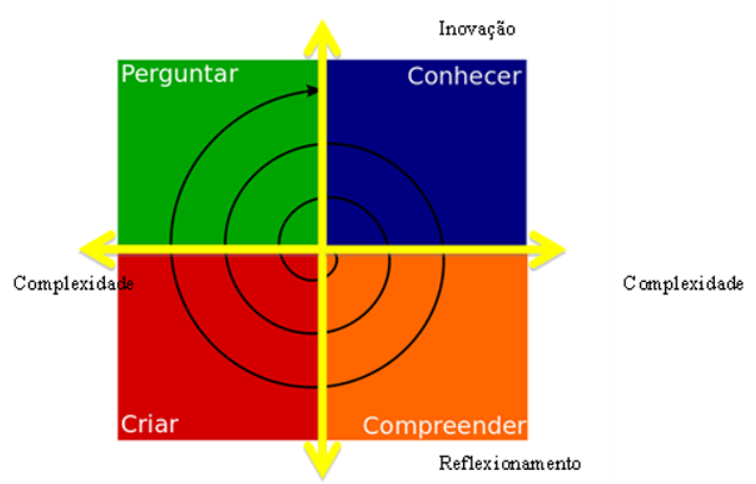

Figura 1. O "ciclone da criação.

Nesse processo de criação é possível reconhecer a evolução da invenção através da abstração reflexionante, descrita por Piaget. O reflexionamento representa os patamares de desenvolvimento da inovação, os quais são 
incrementados a partir das reflexões. E o que desencadeia uma nova reflexão é uma pergunta, ou problema, à qual seguem os momentos de conhecer, compreender e criar. "A característica dessa espiral é, assim, alcançar formas cada vez mais ricas e, consequentemente, mais importantes em relação ao conteúdo" (PIAGET, 1995, p. 275).

Através do "ciclone da criação", busca-se ilustrar como se dá a criação de algo novo, de forma a desmistificar esse processo e torná-lo aplicável em atividades de aprendizagem. O modelo do "ciclone da criação" pode ser utilizado em qualquer nível escolar, pois as crianças e jovens irão utilizar os mecanismos cognitivos que dispõem e que são próprios de cada estágio de desenvolvimento.

\section{CONSIDERAÇõés FINAIS}

Atualmente, muito se fala sobre a relação entre o potencial de inovação, o desenvolvimento econômico e a melhoria das condições de vida da população de um país. O Brasil ocupa uma posição modesta no ranking global de inovação e competitividade econômica, e o motivo disto tem a raiz nos métodos de ensino e de aprendizagem adotados pela educação brasileira.

Com o ingresso da criança no ensino básico, inicia-se uma caminhada ao longo da qual se espera que, começando pelas operações concretas, desenvolvam-se os mecanismos cognitivos que levarão ao pensamento formal. Segundo Jean Piaget, é este que sustenta todas as invenções. Entretanto, métodos ainda muito utilizados, como transmissão de conhecimento, memorização e repetição, não propiciam o desenvolvimento do raciocínio lógico-matemático.

Assim, questiona-se como prover aos estudantes as condições necessárias para que os mesmos possam se tornar sujeitos de inovação? É possível utilizar a teoria de Piaget sobre a construção do conhecimento para fundamentar uma arquitetura pedagógica voltada ao desenvolvimento de jovens inovadores? Quais tecnologias podem auxiliar esse processo? Essas dúvidas, entre tantas outras de ordem econômica, política, social e cultural, necessitam de respostas para que o Brasil passe de consumidor a gerador de inovações.

\section{REFERÊNCIAS}

ALESSANDRINI, Cristina Dias. Análise microgenética da oficina criativa. São Paulo: Casa do Psicólogo, 2004.

BROWN, T. Design thinking: uma metodologia poderosa para decretar o fim das velhas ideias. Rio de Janeiro: Elsevier, 2010.

CHRISTESEN, Clayton M.; DYER, Jeff; GREGERSEN, Hal B. DNA do inovador: dominando as 5 habilidades dos inovadores e ruptura. São Paulo: HSM, 2012.
DE MASI, Domenico. Descoberta e invenção. Rio de Janeiro: Sextante, 2005.

DUMONT, Antonio Santos. Os meus balões. Brasília: Fundação Rondon, 1986.

GALLO, Carmine. A arte de Steve Jobs: pincípios revolucionários sobre inovação para o sucesso em qualquer atividade. São Paulo: Lua de Papel, 2010.

INPI. Manual para depositante de patentes. 2015. Disponível em: <http:/www.inpi.gov.br/menu-servicos/patente/arquivos/ manual-para-o-depositante-de-patentes.pdf $>$. Acesso em: ago. 2015 .

ISAACSON, Walter. Os inovadores: uma biografia da revolução digital. São Paulo: Companhia das Letras, 2014.

JUSTO, J. S. Criatividade no mundo contemporâneo. In: VASCONCELOS, Mário Sérgio (org.). Criatividade: psicologia, educação e conhecimento do novo. São Paulo: Moderna, 2001. p. 59-78.

LA TAILEE, Yves de. O lugar da interação social na concepção de Jean Piaget. In: LA TAILEE, Yves de; OLIVEIRA, Marta Kohl de; DANTAS, Heloisa. Piaget, Vigotsky e Wallon: teorias psicogenéticas em discussão. São Paulo: Summus, 1992. p. 11-21.

MANTOAN, Maria Teresa Égler. Processo de conhecimento: tipos de abstração e tomada de consciência. Memos do NIED, n. 27. Universidade Estadual de Campinas, São Paulo, 1994. Disponível em: <http://www.nied.unicamp.br/ojs/index.php/ memos/article/download/83/82>. Acesso em: ago. 2015.

MONTANGERO, Jacques; MAURICE-NAVILLE, Danielle. Piaget ou a inteligência em evolução. Porto Alegre: ArtMed, 1998.

PIAGET, Jean. A epistemologia genética. Petrópolis: Vozes, 1971.

PIAGET, Jean. A teoria de Piaget. In: MUSSEN, P. H. (org). Psicologia da criança. Desenvolvimento Cognitivo. São Paulo: E.P.U. 1975. Vol. 4, p. 71-117.

PIAGET, Jean. O desenvolvimento do pensamento: equilibração das estruturas cognitivas. Lisboa: Dom Quixote, 1977.

PIAGET, Jean. Desenvolvimento e aprendizagem. Porto Alegre: UFRGS/FACED/DEBAS, 1995.

PIAGET, Jean. Seis estudos de psicologia. 24. ed. Rio de Janeiro: Forense Universitária, 1999.

PIAGET, Jean. Criatividade. In: VASCONCELOS, Mário Sérgio (org). Criatividade: psicologia, educação e conhecimento do novo. São Paulo: Moderna, 2001. p. 11-20.

PIAGET, Jean. Para onde vai a educação. 20. ed. Rio de Janeiro: José Olympio, 2011.

SANTOS, Evanilson Nunes et al. Criatividade e inovação: otimizando uma ferramenta pedagógica. Revista Expressão, n. 5. Disponível em: <http://www4.faculdadepromove.br/expressao/ index.php/files/article/download/29/26>. Acesso em: jun. 2014.

SCHUMPETER, Joseph. A teoria do desenvolvimento econômico: uma investigação sobre lucros, capital, crédito, juro e o ciclo econômico. São Paulo: Nova Cultural, 1997.

Submetido em: 03/09/2015

Aprovado em: 22/02/2016 